\title{
Danos da lagarta Helicoverpa armigera (Hübner, 1805) (Lepidoptera: Noctuidae) em plântulas de soja
}

\author{
Damage caused by caterpillar of Helicoverpa armigera (Hübner, 1805) (Lepidoptera: Noctuidae) to \\ soybean seedlings
}

Renato Anastacio Guazina*, Paulo Eduardo Degrande, Ellen Patrícia Souza \& Evandro Gauer

Universidade Federal da Grande Dourados, Dourados, MS, Brasil. *Autor para correspondência: renato@guazina.com.

Submissão:01/04/2017 / Aceite: 09/04/2018

\begin{abstract}
RESUMO
A soja está sujeita ao ataque da lagarta Helicoverpa armigera durante todo seu ciclo. Quando na fase inicial, pode comprometer o estabelecimento da cultura no campo. Esse estudo teve por objetivo avaliar os danos da lagarta em plântulas de soja, para isso, utilizou-se o delineamento experimental em blocos casualizados com cinco repetições. Os tratamentos foram cinco níveis de infestação: 0, 7, 14, 21 e 28 lagartas $\mathrm{m}^{-2}$. A infestação ocorreu no estádio fenológico cotiledonar (VC) utilizando lagartas de quinto ínstar, e, durante três dias, foram avaliados os danos causados nas hastes, cotilédones e folhas unifolioladas. Já ao final do experimento avaliou-se a altura de plantas, a biomassa e o estande final. Houve danos nas três estruturas vegetativas avaliadas e, em geral, o aumento da população do inseto promoveu aumento no nível de danos, reduzindo o estande, a altura e a biomassa das plântulas de soja. Conclui-se que a lagarta $H$. armigera causa danos severos às plântulas de soja, o que pode afetar o estabelecimento inicial da cultura.
\end{abstract}

PALAVRAS-CHAVE: estande, Glycine max, Heliothinae, Injúria.

\begin{abstract}
Soybean plants are susceptible to the attack of Helicoverpa armigera caterpillars throughout their cycle, including during early developmental stages, which can compromise their settling in the field. This study aimed to assess the damage caused by caterpillars to soybean seedlings. A randomized block design with five replicates was used and the treatments consisted of five levels of infestation: 0, 7, 14, 21 and 28 caterpillars $/ \mathrm{m}^{-2}$. The infestation occurred in the cotyledon stage (VC), using fifth instar caterpillars. For three days, all damage caused to the stem, cotyledon, and unifoliates was evaluated. By the end of the experiment, seedling height, biomass, and the final stand value were determined. Damage was observed in the three vegetative structures and, in general, increase in insect population promoted higher levels of damage, reducing stand, height, and biomass of seedlings significantly. Thus, $H$. armigera caterpillars cause severe damage to soybean seedlings, which may affect their early establishment.
\end{abstract}

KEYWORDS: stand, Glycine max, Heliothinae, injury.

\section{INTRODUÇÃO}

Helicoverpa armigera (Hübner 1805) (Lepidoptera: Noctuidae) é uma espécie amplamente distribuída em regiões de clima tropical e subtropical, com ocorrência em países da Europa, Ásia, África, Oceania e América Latina. No Brasil foi identificada durante a safra 2013/2014 (CZEPAK et al. 2013a), no entanto, essa praga provavelmente já ocorria no país desde 2008, segundo SOSÁ-GOMEZ et al. (2016). Trata-se de uma espécie de lepidóptero polífago (ÁVILA et al. 2013) e com alta capacidade de dispersão (FENG et al. 2004), características que podem colaborar com a dinâmica populacional e condição de praga agrícola, uma vez que, as populações podem dispersar e desenvolver simultaneamente em diferentes plantas hospedeiras dentro de uma região ou podem persistir no ambiente em baixa densidade em áreas aparentemente inadequadas até a fêmea encontrar um hospedeiro capaz de sustentar o desenvolvimento das lagartas (MOSCARDI et al. 2012).

Os prejuízos causados pela $H$. armigera às culturas são significativos e estão relacionados aos danos provocados pelas lagartas aos órgãos vegetativos e reprodutivos das plantas. Há registros na literatura da 
lagarta se alimentando de folhas, flores, vagens e frutos (SARWAR et al. 2009, PRATISSOLI et al. 2015) de culturas agrícolas em geral. Além desses, há relatos que a lagarta pode atacar as plântulas de soja, alimentando-se dos cotilédones (CZEPAK et al. 2013b), o que poderia afetar o bom desenvolvimento inicial da cultura, interferindo na população de plantas recomendada para cada cultivar. Isso geralmente ocorre quando não há limitações climáticas, especialmente baixas temperaturas, e contínuo fornecimento de alimentos, principalmente quando se realiza os sistemas de sucessão e de rotação de culturas que são hospedeiras da praga, permitindo a continuidade do inseto entre uma safra e outra (SUZANA et al. 2015).

A ocorrência de insetos-pragas na fase inicial de qualquer cultura pode causar sérios prejuízos às lavouras, pois acarreta na redução do estande ideal de plantas, o que reflete diretamente na produtividade e, também, ocorre a desuniformidade de espaçamento entre plantas na linha de plantio, favorece o desenvolvimento de plantas daninhas e pode resultar em plantas muito ramificadas e de altura reduzida, 0 que eleva as perdas no momento da colheita (TOURINO et al. 2002).

Com base nestes pressupostos, este trabalho foi conduzido para conhecer a relação entre inseto e planta na fase inicial da cultura da soja, para caracterizar o ataque, bem como investigar a capacidade de danos da lagarta $H$. armigera.

\section{MATERIAL E MÉTODOS}

O experimento foi realizado no Laboratório de Entomologia Aplicada da Universidade Federal da Grande Dourados (UFGD), em condições de casa-de-vegetação, tendo como tratamentos cinco níveis de infestação: $0,1,2,3$ e 4 lagartas por bandeja $\left(0,49 \mathrm{~m} \times 0,30 \mathrm{~m} \approx 0,15 \mathrm{~m}^{2}\right)$, equivalendo a $0 \mathrm{e}$ aproximadamente 7, 14, 21 e 28 lagartas $\mathrm{m}^{-2}$, respectivamente. Foi empregado o delineamento em blocos casualizados com cinco repetições, portanto, cada unidade experimental foi representada por uma bandeja plástica contendo os respectivos níveis de infestação de lagartas $H$. armigera.

Foi utilizada a cultivar de soja BRS Potência RR, que foi semeada nas bandejas plásticas contendo $1 / 3$ de solo, $1 / 3$ de areia fina e $1 / 3$ de substrato orgânico, sendo previamente corrigida a acidez e fertilidade conforme a exigência da cultura. Foram semeadas 12 sementes e, após o desbaste, permaneceram sete plântulas por bandeja, seguindo a recomendação da cultivar de 300.000 plantas ha ${ }^{-1}$. Para evitar a contaminação por fungos, antes da semeadura, foi realizado o tratamento de sementes com fungicida (Carbendazim) na dose de $100 \mathrm{ml}$ do produto comercial para $100 \mathrm{~kg}$ de sementes.

A infestação das lagartas foi realizada no estádio fenológico cotiledonar (VC), momento em que os cotilédones se apresentavam completamente desenvolvidos e com as bordas do par de folhas unifolioladas não se tocando (FARIAS et al. 2007), colocando as lagartas de quinto ínstar no centro de cada bandeja. Os ovos de $\mathrm{H}$. armigera foram adquiridos da empresa BUG Agentes Biológicos e mantidos em sala de criação com condições controladas de temperatura $\left(25 \pm 2{ }^{\circ} \mathrm{C}\right)$, umidade $(70 \pm 10 \%)$ e fotofase de 12 horas. Após a eclosão, as lagartas foram alimentadas com dieta artificial proposta por VILELA et al. (2014) até o momento da infestação.

Após a infestação foram realizadas três avaliações, sendo elas as 24, 48 e 72 horas após a infestação para determinar o nível de lesão na haste, cotilédones e folhas unifolioladas. As lesões foram classificadas em: nenhuma lesão (1), pouca lesão (2) e lesão severa (3) (BORTOLOTTO et al. 2014). No final do experimento foi realizada a avaliação do número de plântulas remanescentes (para estimativa da redução do estande). Também foi determinada a altura ( $A L)$ das plântulas a partir da base do solo até a extremidade apical da haste principal e a biomassa em matéria seca (MS) e fresca (MF) das plantas após 20 dias da infestação.

A análise dos dados foi realizada pelo programa estatístico Sisvar empregando Análise de Regressão em função dos níveis de infestação.

\section{RESULTADOS E DISCUSSÃO}

As equações de regressão e os coeficientes de determinação resultantes das análises de regressão para todos os parâmetros relacionados aos danos nas hastes, cotilédones e folhas unifolioladas estão apresentados nas Figuras 1, 2 e 3 . Os resultados obtidos neste estudo indicam, de modo geral, que o aumento do nível de infestação da lagarta $H$. armigera aumenta significativamente os danos nas três estruturas vegetativas mencionadas anteriormente.

Na primeira avaliação, realizada 24 horas após a infestação (Figura 1), os dados referentes aos danos nos cotilédones e folhas unifolioladas ajustaram-se a equação quadrática $(p<0,05)$, ou seja, os danos foram mais severos à medida que houve aumento do número de lagartas. As injúrias foram observadas a partir do tratamento com 14 lagartas $\mathrm{m}^{-2}$, sendo que apenas no tratamento com 28 lagartas $\mathrm{m}^{-2}$ houve o 
consumo total dos cotilédones (lesão severa). Nas folhas unifolioladas foram observadas poucas lesões mesmo no maior nível de infestação (28 lagartas $\left.\mathrm{m}^{-2}\right)$. Na haste das plântulas não foram observadas lesões, portanto, nota-se que inicialmente as lagartas preferem se alimentar dos cotilédones e folhas unifolioladas.

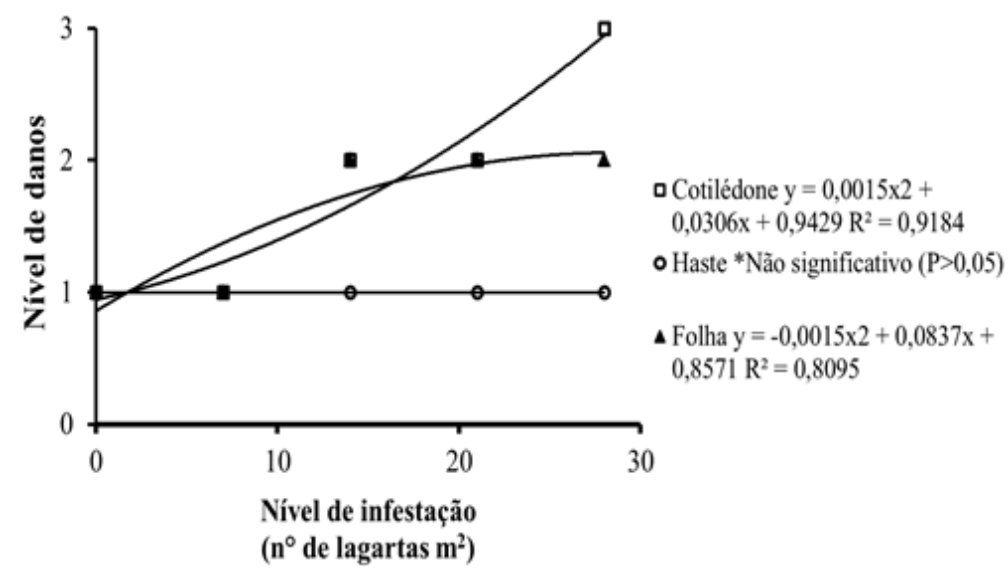

Figura 1. Danos causados pela lagarta $H$. armigera no cotilédone, haste e folha unifoliolada de plântulas de soja após 24 horas da infestação.

Figure 1. Damage caused by the $\mathrm{H}$. armigera caterpillar on the cotyledon, stem and unifoliate leaf of soybean seedlings after 24 hours of infestation.

$\mathrm{Na}$ segunda e terceira avaliações, realizadas 48 e 72 horas respectivamente, após a infestação (Figuras 2 e 3), os dados referentes aos danos no cotilédone, haste e folha unifoliolada foram semelhantes e ajustaram-se a equação polinomial de $2^{\circ}$ grau $(p<0,05)$. Foram observadas nos tratamentos com $14,21 \mathrm{e}$ 28 lagartas $\mathrm{m}^{-2}$ um intenso ataque nos cotilédones e folhas unifolioladas, causando lesões severas com a eliminação total dessas estruturas. Em decorrência da pouca oferta de alimentos foram observadas injúrias na haste das plântulas de soja nos tratamentos a partir de 21 lagartas $\mathrm{m}^{-2}$, sendo que as lesões severas foram observadas no tratamento com 28 lagartas $\mathrm{m}^{-2}$.

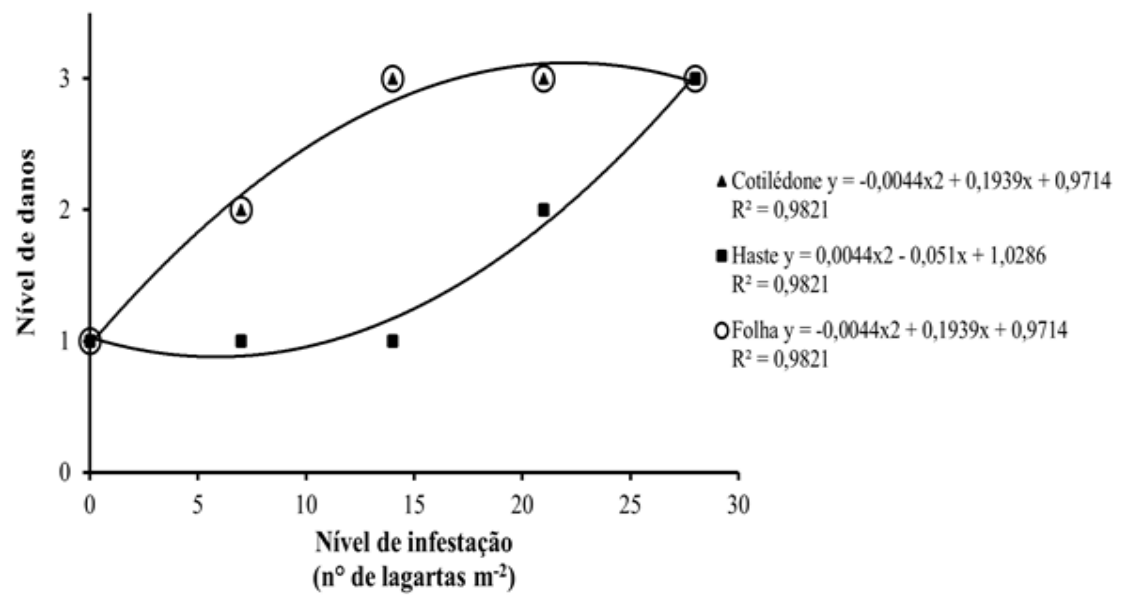

Figura 2. Danos causados pela lagarta $H$. armigera no cotilédone, haste e folha unifoliolada de plântulas de soja após 48 horas da infestação.

Figure 2. Damage caused by the $H$. armigera caterpillar on the cotyledon, stem and unifoliate leaf of soybean seedlings after 48 hours of infestation.

Os resultados obtidos nesse estudo confirmam que a lagarta $H$. armigera pode atacar a soja em fase de plântula, conforme referido por CZEPAK et al. (2013b). No entanto, as lagartas podem atacar além dos cotilédones, conforme foi mencionado por esses autores, as folhas unifolioladas e haste. Notou-se que após a infestação as lagartas iniciam a alimentação na região superior das plântulas (cotilédones e folhas unifolioladas) e somente após o consumo dessas estruturas ocorre 0 ataque na haste. Esse comportamento da lagarta $H$. armigera em iniciar a alimentação da região superior da planta também foi verificado por ROGERS \& BRIER (2010). Resultados semelhantes também foram observados no estudo realizado por BORTOLOTTO et al. (2014) que ao avaliarem os danos da lagarta Heliothis virescens (Lepidoptera: 
Noctuidae) em plântulas de soja, observaram maior preferência de alimentação na região de crescimento da planta (região apical). Esses autores sugerem que a região apical da planta seja mais atrativa para a lagarta, atribuindo ser mais palatável e ter maior valor nutricional.

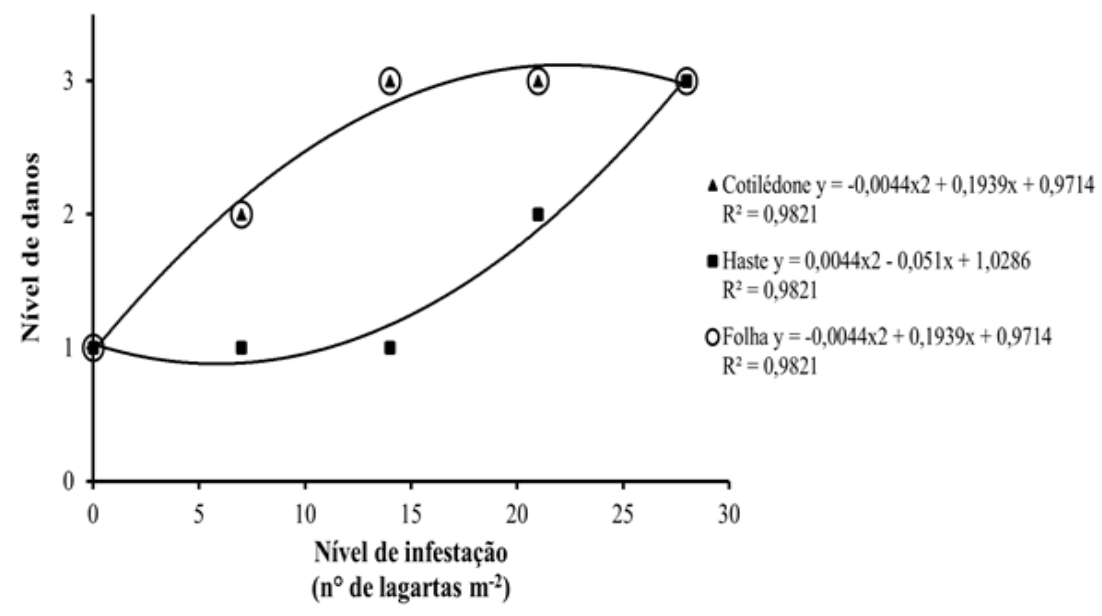

Figura 3. Danos causados pela lagarta $H$. armigera no cotilédone, haste e folha unifoliolada de plântulas de soja após 72 horas da infestação.

Figure 3. Damage caused by the $\mathrm{H}$. armigera caterpillar on the cotyledon, stem and unifoliate leaf of soybean seedlings after 72 hours of infestation.

A forma de ataque da $H$. armigera na haste das plântulas de soja, que inicia da região apical caulinar para o colo da plântula, difere dos ataques de outras espécies de lagartas que também ocorrem nessa fase de desenvolvimento da soja, como a Agrotis ipsilon e Spodoptera frugiperda, que têm o hábito de cortar e até seccionar o colo da plântula logo abaixo da superfície do solo (GALLO et al. 2002), FORMENTINI et al. 2015).
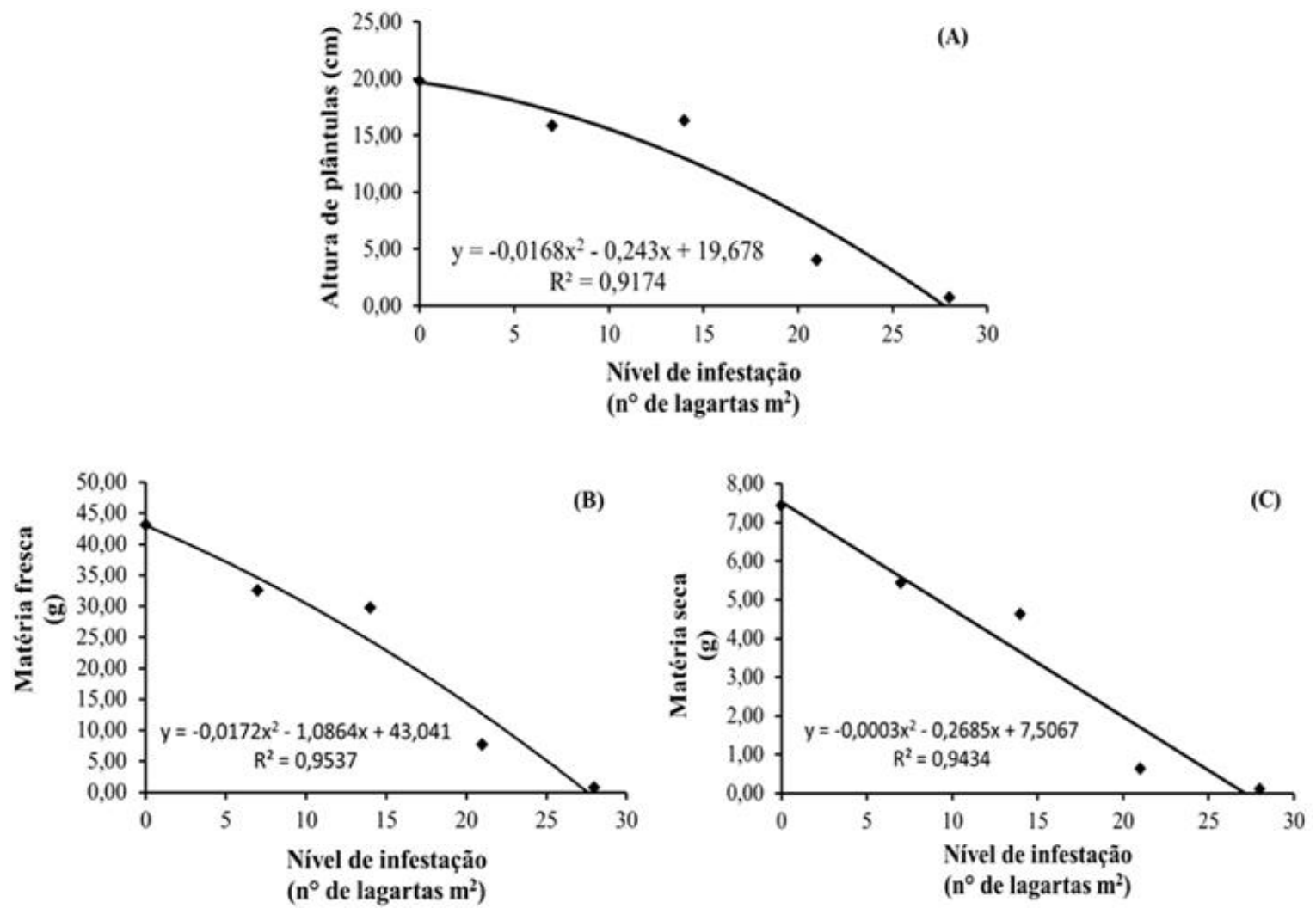

Figura 4. Altura de plantas (A), matéria fresca $(B)$ e seca $(C)$ em diferentes níveis de infestação da lagarta $H$. armigera.

Figure 4. Height of plants $(A)$, fresh $(B)$ and dry matter $(C)$ for different infestation levels of $H$. armigera caterpillar. 
As curvas de AL, MS e MF das plântulas de soja submetidas a diferentes níveis de infestação da lagarta $H$. armigera apresentaram ajuste a equação de $2^{\circ}$ grau $(p<0,05)$ (Figura 4). Constatou-se que as curvas de AL, MS e MF, houve redução nessas três variáveis com o aumento do nível de infestação das lagartas, sendo que os menores valores foram observados nos níveis de infestação com 21 e 28 lagartas $\mathrm{m}^{-2}$, provavelmente, devido aos danos severos provocados nas plântulas de soja. Segundo THOMAS \& COSTA (1993) os cotilédones são fundamentais para o crescimento das plântulas de soja até o $11^{\circ}$ dia após a emergência, sendo reserva de nitrogênio para o desenvolvimento da planta. Outra possível explicação seria relacionada aos danos na haste, principalmente, na região apical, onde se encontra o meristema caulinar, que tem função importante no crescimento das plantas. Conforme TANCREDI et al. (2006) a remoção do meristema apical foi capaz de reduzir a altura de plantas de soja.

Observou-se uma tendência de redução no número de plantas (estande) com o aumento do número de lagartas, ajustando a equação polinomial de $2^{\circ}$ grau $(p<0,05)$ (Figura 5$)$. Nos tratamentos com infestações de 7 e 14 lagartas $\mathrm{m}^{-2}$ a redução no estande foi de $3 \%$, já nos tratamentos com 21 e 28 lagartas $\mathrm{m}^{-2}$ houve reduções de $54 \%$ e $91 \%$, respectivamente. A população de plantas está diretamente relacionada com a produção de grãos, sendo caracterizado com um componente produtivo, no entanto, a cultura da soja é capaz de suportar grandes reduções de populações sem perdas significativas na produtividade (HOSSEINI et al. 2001, VAZQUEZ et a. 2008). VAZQUES et al. (2008) observaram que dependendo da cultivar a soja pode suportar reduções na população de plantas de até $45 \%$, como foi visto na cultivar Vencedora. Portanto, pode-se inferir, com base nas populações de plantas observadas nesse estudo, que a partir de 21 lagartas $\mathrm{m}^{-2}$ haveria redução significativa na produtividade de grãos de soja.

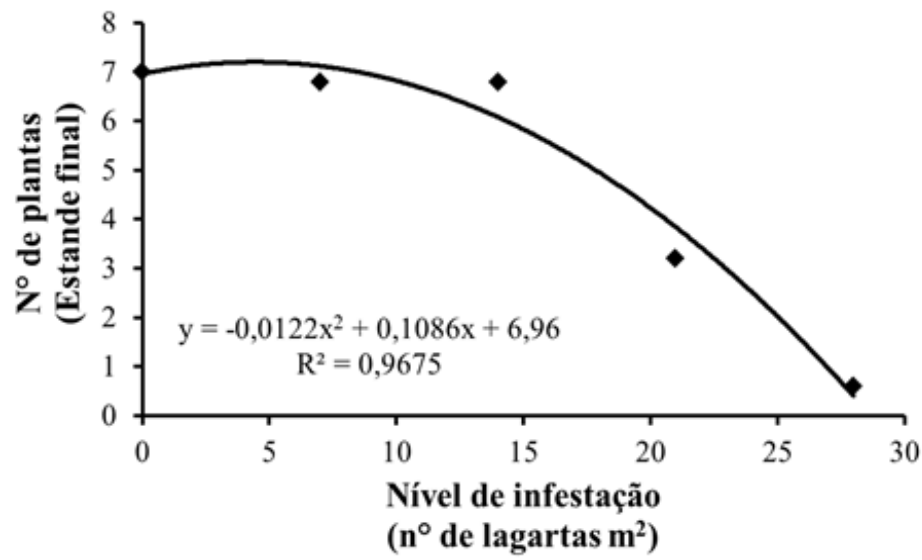

Figura 5. Número de plantas (estande) no final do experimento, após 20 dias da infestação, nos respectivos níveis de infestação de lagartas $H$. armigera.

Figure 5. Number on plants (stand) at the end of the experiment, after 20 days of infestation, in the respective infestation levels of $\mathrm{H}$. armigera caterpillars.

\section{CONCLUSÃO}

A lagarta Helicoverpa armigera causa danos severos às plântulas de soja, consumindo folhas unifolioladas, cotilédones e haste, incluindo repercussão em diminuição ou qualidade do estande de plantas.

\section{REFERÊNCIAS}

ÁVILA CJ et al. 2013. Ocorrência, aspectos biológicos, danos e estratégias de manejo de Helicoverpa armigera (Hübner) (Lepidoptera: Noctuidae) nos sistemas de produção agrícolas. Dourados: Embrapa Agropecuária Oeste. 12p. (Circular Técnica, 23).

BORTOLOTTO OC et al. 2014. Biological characteristics of Heliothis virescens fed with Bt-soybean MON 87701 x MON 89788 and its conventional isoline. Anais da Academia Brasileira de Ciências 86: 973-980.

CZEPAK C et al. 2013a. Primeiro registro de ocorrência de Helicoverpa armigera (Hübner) (Lepidoptera: Noctuidae) no Brasil. Pesquisa Agropecuária Tropical 43: 110-113.

CZEPAK C et al. 2013b. Praga da vez. Cultivar: grandes culturas. 167: 20-27.

FARIAS JRB et al. 2007. Ecofisiologia da soja. Londrina: Embrapa. 9p. (Circular Técnica, 48).

FENG H. et al. 2004. Northward migration of Helicoverpa armigera (Lepidoptera: Noctuidae) and other moths in early summer observed with radar in northern China. Journal of Economic Entomology 97: 1874-1883.

FORMENTINI AC et al. 2015. Lepidoptera (Insecta) associated with soybean in Argentina, Brazil, Chile and Uruguay. Ciência Rural 45: 2113-2120.

GALLO D et al. 2002. Entomologia Agrícola. Piracicaba: FEALQ. 920p. 
HOSSEINI NM et al. 2001. Effects of plant population density on yield and yield components of eight isolines of cv. Clark (Glycine max L.). Journal of Agricultural Science and Technology 3: 131-139.

MOSCARDI $F$ et al. 2012. Artrópodes que atacam as folhas da soja. In: HOFFMANN-CAMPO BC et al. Soja: manejo integrado de insetos e outros artrópodes-praga. Brasília: Embrapa. p.213-333.

PRATISSOLI D et al. 2015. Occurrence of Helicoverpa armigera (Lepidoptera: Noctuidae) on tomate in the Espírito Santo state. Horticultura Brasileira 33: 101-105.

ROGERS DJ \& BRIER HB. 2010. Pest-damage relationships for Helicoverpa armigera (Hübner) (Lepidoptera: Noctuidae) on soybean (Glycine max) and dry bean (Phaseolus vulgaris) during pod-fill. Crop Protection 29: 47-57.

SARWAR M et al. 2009. Host plant resistance relationshiphs in chickpea (Cicer arietinum L.) against gram pod borer (Helicoverpa armigera Hubner). Pakistan Journal of Botany 41: 3047-3052.

SOSA-GÓMEZ DR et al. 2016. Timeline and geographical distribution of Helicoverpa armigera (Hübner) (Lepidoptera: Noctuidae: Heliothinae) in Brazil. Revista Brasileira de Entomologia 60: 101-104.

SUZANA CS et al. 2015. Desempenho de larvas de Helicoverpa armigera (Hübner) (Lepidoptera: Noctuidae) em diferentes fontes alimentares. Pesquisa Agropecuária Tropical 45: 480-485.

TANCREDI FD et al. 2006. Efeito da remoção do meristema apical no crescimento e desenvolvimento de plantas de soja em condições de casa de vegetação. Bioscience Journal 22: 53-60.

THOMAS AL \& COSTA J A. 1993. Crescimento de plântulas de soja afetado pelo sombreamento dos cotilédones e suas reservas. Pesquisa Agropecuária Brasileira 28: 925-929.

TOURINO MCC et al. 2002. Espaçamento, densidade e uniformidade de semeadura na produtividade e características agronômicas da soja. Pesquisa Agropecuária Brasileira 37: 1071-1077.

VAZQUEZ GH et al. 2008. Redução na população de plantas sobre a produtividade e a qualidade fisiológica da semente de soja. Revista Brasileira de Sementes 30: 1-11.

VILELA M et al. 2014. Metodologia para criação e manutenção de Helicoverpa armigera em laboratório. Sete Lagoas: Embrapa Milho e Sorgo. 7p. (Circular Técnica, 203). 